\title{
Pulmão murcho, manchado ou esburacado? Concepções sobre a DPOC entre idosos de classe popular no Distrito Federal
}

Resumo: As Doenças Pulmonares Obstrutivas Crônicas (DPOC) configuram uma das mais significativas causas de morbidade crônica e mortalidade no Brasil. Há um esforço das áreas biomédicas e das políticas públicas em abordar esse problema epidemiológico. Contudo, há pouco acúmulo no sentido de uma Antropologia das doenças pulmonares. Nossa equipe entrevistou 28 pessoas que tinham recebido o diagnóstico de DPOC, que já frequentavam habitualmente o Ambulatório da Pneumologia de um grande hospital universitário e recebiam o serviço de oxigenoterapia. Nesse artigo, a ideia é oferecer um aporte antropológico à discussão sobre a DPOC para conhecer como essas pessoas percebiam seus pulmões, entendiam a doença e vislumbravam o futuro com a mesma. Essas concepções sobre anatomia e adoecimento são fundamentais para entendermos a relação com os medicamentos, a adesão aos tratamentos, a relação com os profissionais de saúde e, assim, melhor modularmos o acolhimento e tratamento a esse público, em geral, idoso.

Palavras-chave: DPOC; Pulmão; Antropologia; Distrito Federal. 


\title{
Withered, stained or potholed lung? Conceptions about COPD among low-income elderly in the Federal District
}

\begin{abstract}
Chronic Obstructive Pulmonary Diseases (COPD) are one of the most significant causes of chronic morbidity and mortality in Brazil. There is an effort by the biomedical areas and by public policy to address this epidemiological problem. However, there is little literature from Anthropology. Our team interviewed 28 people who had been diagnosed with COPD, who were already attending the Pulmonary Outpatient Clinic of a large university hospital and receiving oxygen therapy. In this article, the goal is to offer an anthropological contribution to the discussion about COPD, to know how these people perceived their lungs, understood the disease and envisioned the future living with it. These conceptions about anatomy and illness are central to understand the relationship with medications, adherence to treatments, relationship with health professionals and, therefore, better modulate the reception and treatment of this elder public.
\end{abstract}

Key-words: COPD; Lungs; Anthropology; Federal District (Brazil)

\section{¿Pulmón marchito, manchado o con baches? Concepciones sobre la EPOC entre los ancianos de bajos ingresos en el Distrito Federal}

\begin{abstract}
Resumen: Las enfermedades pulmonares obstructivas crónicas (EPOC) son una de las causas más importantes de morbilidad y mortalidad crónicas en Brasil. Las áreas biomédicas y las políticas públicas se esfuerzan por abordar este problema epidemiológico. Sin embargo, existe poca investigación hacia una antropología de las enfermedades pulmonares. Nuestro equipo entrevistó a 28 personas que habían sido diagnosticadas con EPOC, que ya habían asistido a la clínica de neumología para pacientes ambulatoriales de un gran hospital universitario y recibieron el servicio de oxigenoterapia. En este artículo, la idea es ofrecer una contribución antropológica a la discusión sobre la EPOC para saber cómo estas personas percibieron sus pulmones, entendieron la enfermedad e imaginaron el futuro con ella. Estas concepciones sobre la anatomía y la enfermedad son fundamentales para comprender la relación con los medicamentos, la adherencia a los tratamientos, la relación con los profesionales de la salud y, por lo tanto, modular mejor la recepción y el tratamiento para este público, en general, compuesto por ancianos.
\end{abstract}

Palabras clave: EPOC; pulmón; Antropología; Distrito Federal (Brasil). 
A s doenças pulmonares obstrutivas crônicas são "uma das principais causas de morbidade crônica e mortalidade, no Brasil e no mundo" (TORRES et al, 2018: 1). No Brasil, ela já ocupa a quinta posição em causa de mortalidade. Anualmente, morrem cerca de "38 mil pessoas" (SOUSA et al, 2011: 899) e são internadas cerca de "290 mil pacientes, trazendo um gasto enorme ao Sistema de Saúde do país. Tão importante quanto os gastos diretos são os gastos indiretos, computados como dias perdidos de trabalho, aposentadorias precoces, morte prematura e sofrimento familiar e social” (JARDIM et al, 2004: 7). Há um esforço científico das áreas biomédicas bem como uma relativa prioridade das políticas públicas em abordar esse problema epidemiológico. Contudo, há pouco acúmulo no sentido de uma antropologia das doenças "pulmonares". Contamos, para citar alguns exemplos, com um importante clássico, ainda na década de 1940 (NOGUEIRA, 2009 [1949]), e como alguns poucos trabalhos mais recentes no cenário nacional (PINTO ET AL, 2008; GONÇALVES et al, 1999; MARTINS, 2014; FLEISCHER, 2015) e internacional (BECKER et al, 1993), por exemplo.

Essa pesquisa, realizada em 2013, teve como intuito mais geral conhecer as pessoas que tinham recebido o diagnóstico da Doença Pulmonar Obstrutiva Crônica (DPOC) e que já frequentavam habitualmente o Ambulatório da Pneumologia de um grande hospital universitário e recebiam o serviço de oxigenoterapia oferecido pelo SUS. Nesse artigo, a ideia é oferecer um aporte antropológico à discussão sobre a DPOC, no sentido de conhecer como essas pessoas percebiam seus pulmões, entendiam a doença e vislumbravam o futuro com a mesma. Essas concepções sobre anatomia e adoecimento são fundamentais para entender outras, como a relação com os medicamentos, a adesão aos tratamentos, a relação com os profissionais de saúde - todos elementos que precisam continuar a ser estudados em pesquisas futuras. Esses dados oferecem grande oportunidade para lançarmos o olhar da Antropologia às doenças pulmonares, de forma mais circunscrita, e à experiência de adoecimento crônico e continuado, de forma mais geral.

A seguir, serão apresentados a metodologia da pesquisa, o contexto socioeconômico dos 28 entrevistados e as concepções relativas, primeiro, ao órgão afetado; segundo, às razões para a instalação da DPOC; e, por fim, às perspectivas vindouras na convivência com a doença.

\section{Metodologia}

Essa pesquisa foi realizada pari passu à docência. A maior parte da pesquisa foi realizada como uma atividade regular da disciplina de graduação "Antropologia da saúde", oferecida pelo meu Departamento de Antropologia (DAN). A turma, composta por 28 estudantes de diferentes cursos (Antropologia, Sociologia, Saúde Coletiva, Psicologia e Enfermagem), realizou etapas fundamentais de uma pesquisa, como a busca e cobertura bibliográfica, a elaboração do roteiro de entrevistas, a realização do pré-teste do instrumento, a condução das entrevistas, a transcrição do material gravado em áudio, a análise de dados e a escrita de ar- 
tigos científicos. Além disso, foi proposital realizar a disciplina e a pesquisa dentro do hospital universitário para que, desde o início, as estudantes pudessem se familiarizar com a rotina hospitalar. Duas vezes por semana, a turma frequentava os corredores, balcões de atendimento, salas de espera do Ambulatório de Pneumologia e espaços externos ao prédio. ${ }^{2}$

O pré-teste da entrevista, realizado nas dependências do Ambulatório, revelou que as pessoas se sentiram sem privacidade para falar de assuntos dolorosos e delicados na frente de todos ali sentados, mantiveram sua atenção voltada para que a fila de espera fosse respeitada e modularam suas respostas conforme as hierarquias percebidas facilmente dentro do hospital (CHAZAN, 2005; Fleischer, 2018). Assim, a turma optou por realizar as entrevistas na casa das pessoas, prevendo ser mais confortável e menos oneroso se ficassem ali, em vez de terem que vir ao hospital uma outra vez, trajeto exaustivamente realizado por elas no cuidado rotineiro da DPOC. Priorizar à casa ao hospital criou uma inversão importante: permitiu que deixassem de ser apenas "pacientes" para se tornarem narradores em primeira pessoa, contando sobre suas experiências diretas com a DPOC (CHARON, 2006).

A equipe do Ambulatório nos passou uma lista com os nomes e contatos telefônicos das pessoas e as entrevistas foram realizadas por duplas interdisciplinares de estudantes. Além disso, cada entrevista gerava um "diário de campo", ferramenta fundamental da Antropologia (MALINOWSKI, 1984 [1922]; CARDOSO DE OLIVEIRA, 1998). Uma coisa são as entrevistas transcritas, um texto literal, muito próximo ao que foi dito pela entrevistada. Outra coisa é o registro de informações não necessariamente audíveis ou verbalizadas. A atmosfera da entrevista, os assuntos tratados antes e depois de o aparelho de gravação ser ligado, as reações sentidas pela entrevistadora, a experiência de fazer pesquisa como parte de uma disciplina de graduação são todos detalhes a serem registrados nos diários de campo. Ao todo, 28 pessoas foram entrevistadas, muitas vezes em companhia de seus cuidadores, em geral esposa, filha e/ou neta. A todas elas, foi apresentado o termo de consentimento livre e esclarecido para conhecimento e assinatura. Como a grande maioria de entrevistadoras, entrevistadas, cuidadoras e profissionais de saúde são mulheres, nesse artigo optamos por seguir o plural feminino. A única atividade que foi realizada antes dessa disciplina começar foi a submissão do projeto de pesquisa ao Comitê de Ética em Pesquisa em Ciências Humanas e Sociais (CAAE 13702613.0.0000.5540).

\section{Contexto socioeconômico}

Vale apresentar um panorama socioeconômico sobre as 28 pessoas entrevistadas. 21 das entrevistadas eram mulheres e apenas 7, homens. A grande maioria era idosa, com mais de 60 anos de idade, com uma média de 67 anos de idade. Elas vinham de todas as regiões do país (exceto da Região Norte) e com predominância dos estados de Minas Gerais e do Nordeste. A maioria das pessoas veio um

\footnotetext{
${ }^{2}$ A disciplina contou ainda com a participação de Raysa Martins, à época mestranda do Programa de Pós-Graduação em Antropologia Social, como assistente de pesquisa; Natharry Almeida, graduanda em Ciências Sociais que participou como monitora discente; e Antônio Cyrino, médico e professor do curso de Medicina da UNESP em Botucatu/SP, em estágio pós-doutoral no DAN. A equipe de pesquisadoras foi composta por: Bruna Lima, Caio Capella, Darlene Moura, Fernanda Benedete, Hugo Fernando, Jackeline Magalhães, Jéssica Souza, Monique Batista, Laísa Almeida, Letícia Carlos, Letícia Dias, Lilian Macedo, Luana Galeno, Lucas Wandenkolck, Marcia França, Marina Flores, Mayara Martins, Monique Mesquita, Natharry Almeida, Paulo Coutinho, Priscila Duhau, Rafaela Raposo, Sanlai Nascimento, Stéfane Guimarães, Tamara Campos, Thalita Anjos, Thayse Caires e Yuri Corteletti. Aproveitamos para agradecer à toda a turma da pesquisa, bem como a todas as pessoas entrevistadas, suas respectivas famílias e a equipe do Ambulatório de Pneumologia do Hospital Universitário.
} 
pouco antes da inauguração da capital federal (3) e logo nas primeiras duas décadas da nova capital (9 na década de 1960 e 8, de 1970). Sete pessoas vieram nas décadas de 1980, 1990 e 2000 - possivelmente já doentes para viver com os filhos e receber tratamento. Excepcionalmente, uma pessoa estava em Minas Gerais e vinha até a capital especialmente para as consultas. À época da pesquisa, a maioria das entrevistadas vivia em regiões mais distantes do centro da cidade, onde está o hospital universitário. Assim, 21 pessoas precisam percorrer grandes distâncias para chegar à consulta, reabastecer as "balas" de oxigênio ou receber uma internação. Moravam entre 10 e 50 quilômetros do hospital.

Quanto ao estado civil, 18 pessoas eram casadas. Cinco eram viúvas, duas haviam se separado e três eram solteiras. Vale mencionar que duas das viúvas haviam chegado mais recentemente ao DF para, justamente, morar com os filhos e receber seus cuidados. Das pessoas que não tinham cônjuges à época da pesquisa, todas contavam com familiares (filhas e netas, especialmente) morando por perto. Quase a totalidade das entrevistadas tinha filhas (26 das 28) morando proximamente. Destas, as filhas eram todas adultas. A maior parte das entrevistadas professava alguma fé, sendo católicas (15), evangélicas (8), espíritas (3), budista (1) e uma se identificou como "católica e crente" ao mesmo tempo. Algumas das católicas se disseram não praticantes. Ninguém se definiu como "sem religião".

Muitas das mulheres da pesquisa se definiram como "donas de casa" (10). Isso implicava que, embora pudessem ter trabalhado fora do âmbito doméstico e de forma remunerada, ainda figuravam como principais responsáveis pelo trabalho doméstico na própria casa. Outras atuaram como costureiras (2); lavadeira (1); lavradora (1); faxineira (1); comerciária (1); comerciante (1). Com diploma de ensino médio completo, duas haviam sido técnicas administrativas. Com nível de ensino superior, entrevistamos uma psicóloga e uma professora secundarista. Os homens tiveram ocupações como: comerciário (1), marceneiro (1), sapateiro (1), pedreiro (1), trabalhador de fábrica de cimento (1) e técnico em manutenção (1), motorista (1). Vale lembrar que várias dessas profissões lidam com muita poeira e/ou substâncias tóxicas, como cola para sapato, serragem de madeira, pó de cimento, poeira doméstica, penugem de tecido, agrotóxicos, sabão, produtos químicos de limpeza, fogão à lenha etc. Esse é um dado central no desenvolvimento da DPOC, como se verá adiante.

O conjunto de entrevistadas conta, em geral, com pouca ou nenhuma escolaridade. Sete eram iletradas ( 5 mulheres e 2 homens); 6 não haviam terminado o nível fundamental de ensino ( 5 mulheres e 1 homem); 4 tinham o fundamental completo ( 3 mulheres e 1 homem); uma mulher e dois homens não chegaram a terminar o ensino médio e uma mulher, sim. Duas mulheres tinham o curso superior completo.

\section{Resultados e discussão: Conjuntos de concepções relativas às doenças pulmonares}

Em primeiro lugar, seguindo os preceitos básicos da Antropologia da Saúde (IBÁÑEZ-NOVIÓN et al, 2012; DUARTE, 1988), é muito importante considerar como o órgão do pulmão era concebido, imaginado, ilustrado por essas pessoas, já que se tratava do órgão a concentrar as doenças que estavam sendo vivenciadas. Em segundo lugar, havia um conjunto de causas que estas pessoas identificavam para o surgimento e desenvolvimento dessas doenças pulmonares, em especial da DPOC. Esses dois conjuntos - imagens do órgão e explicações para o 
adoecimento - eram absolutamente inter-relacionadas e fundamentais para que se compreendesse como essas pessoas entendiam (ou não) os diagnósticos recebidos e aderiam (ou não) aos tratamentos prognosticados. Aqui, fica claro que, mesmo que o diálogo com as autoridades biomédicas fosse central na relação com as doenças e também com os serviços de saúde da cidade, é preciso lembrar que também construíam suas próprias imagens do corpo e do adoecimento que poderiam preceder e ultrapassar as concepções fisicalistas sobre as DPOC que provêm da biomedicina. Muitas vezes, os ruídos de comunicação e de tratamento advinham do desconhecimento e da indisponibilidade das equipes de saúde para compreender a percepção dos pacientes.

\section{As imagens sobre o pulmão}

Notamos sete imagens elaboradas por essas pessoas para representarem o pulmão. São metáforas que funcionam de modo bastante concreto na tentativa de imaginar como era esse órgão que estava dentro do corpo e que se experienciava de forma sensorial a cada respiração, mas que não era parte exatamente visível ao olho nu. Compreendemos essas imagens como tentativas de formular explicações para a situação em que o pulmão se encontrava, após anos de adoecimento. Os substantivos, adjetivos e caracterizações imagéticas - como elástico, balão, buraco, buchinha, parede, mancha - funcionam bem como metáforas. Conseguem comunicar sensações e sentimentos porque conseguem "inventar similaridade onde não existia previamente" (SCHUSTERA et al, 2011: 585). Abaixo, para facilitar a visualização e o entendimento, foram arrolados exemplos encontrados ao longo das entrevistas que melhor expressassem as ideias contidas nas metáforas.

Uma das perguntas do roteiro foi "Como a médica explica a doença à senhora?" Por isso, muitas das respostas se referem a "ela me disse", "ela me explicou", "a médica me contou" etc. As imagens descritas pelas entrevistadas eram, portanto, influenciadas pelo encontro clínico e hospitalar, no consultório e durante as internações. Constituem interpretações, reelaborações de várias informações que receberam nos hospitais, mas também em conversas com outros adoecidos, com seus familiares, na sala de espera, pela vizinhança e visitações à terra natal etc.

A cor preta foi apontada como sinal de severidade. As radiografias, embora sejam todas em P\&B, foram indicadas como material visual que auxiliou na localização e imaginação dessas doenças. Quanto mais a cor preta predominasse na imagem e quanto mais intensa fosse essa coloração, mais era tida como grave a DPOC. Além disso, foram usadas técnicas visuais para explicar a situação dos pulmões. As pessoas mencionaram ter visto, no computador da médica, retratos, que os pulmões foram desenhados num quadro, que um filme lhes foi transmitido no consultório ou em palestras. Ainda nesse registro visual, atentamos para o fato de que falam, em geral, no plural, "pulmões", a dupla formada pelo pulmão esquerdo e o direito. Se apenas um pulmão fosse acometido, a situação era percebida como menos grave e mais fácil de lidar. 
IMAGENS

DO PULMÃO

1. Pulmão murcho, seco
TRECHOS

\section{DAS ENTREVISTAS}

Era o pulmão esquerdo, que é murcho, o fôlego não vai até lá, por isso que é pequenininho. E quando você respira, o ar não vai lá. $\mathrm{Na}$ época, morreu o elástico e fechou. Mas era só o esquerdo. (Mulher, lavradora aposentada, 70 anos)

A doutora diz que eu tenho encolhimento do pulmão, é como se eu tivesse só $50 \%$ do pulmão funcionando. Ele bate o raio $X$ e vê. É só andar um pouco e já fico cansada, por isso uso minha bengala, porque eu descanso um pouco com ela. (Mulher, 58 anos, autônoma, casada)

A doutora disse que é um pedacinho do pulmão que vai secando. Aí, dá isso. (Mulher separada e dona de casa, 70 anos)

2. Pulmão colado

Eles entraram com um medicamento para tentar dilatar porque tinha colado o pulmão. Se não desse certo, eles teriam que fazer aquela traqueostomia. Eles entraram com medicamento, era uma bombinha e conseguiram dilatar e não precisou furar. (Mulher)

3. Pulmão inchado

Eu fico com falta de ar, mas não é nada de bactéria. A médica disse que o pulmão inchou. (Mulher, 60 anos, goiana, casada, costureira, três filhos)

4. Pulmão esburacado A doutora explicou pro meu pai e pra minha mãe sobre o enfisema em si, ficava cheio de buraco o pulmão, como se fosse um balão, cheio de buraco. (Mulher, aposentada, divorciada)

A vovó já teve tuberculose. Aí, eles confundem, pegam o raio $X$ e vê que o pulmão dela está cheio de buraquinhos, todo perfurado por causa da tuberculose que foi há muito tempo atrás. Mas como não tinha o tratamento que tem hoje, ficou bem danificado o pulmão dela. Além de tudo, ela tem asma grave. Aí todo mundo se assusta, acho logo que é uma coisa mais séria. (Neta cuidadora de senhora viúva e católica de 86 anos)

A médica me explicou que quando eu tive essa doença, eu comecei um tratamento e não terminei. Então, ele foi só se aprofundando, meu pulmão é cheio de cavidade. Por isso que eu tenho esse problema, qualquer poeirinha, qualquer coisa que eu pego, esses buraquinhos ficam piores. (Mulher, 44 anos, cearense, não trabalha, casada, uma filha)

5. Pulmão coberto, tam- $\quad$ Fumaça de cigarro tampou o pulmão. A médica até me ensinou assim, "Você toma banho pado, fechado, obstruído Eu digo, "Tem". Ai ela falou, "Você tampou aqueles buraquinhos que você tinha tudinho com a fumaça do cigarro". Ela me explicou tudinho assim. (Mulher)

Ah, melhorou em algumas coisas. Hoje, eu tenho um ar, uma respiração mais aberta, entendeu? Antes, era como uma coisa fechada, como se fosse uma parede, uma coisa fechada. Uma coisa me sufocando. (Mulher)

Tinha dia que não dava para fazer nada porque eu sentia um fechamento lá dentro, assim, arrochando. Eu sentia por dentro, fechando. (Mulher lavradora aposentada, 70 anos)

A fibrose ataca o pulmão porque obstrui, acaba com uma parte do pulmão. (Homem)

6. Pulmão manchado A doença da minha cunhada foi uma doença mal curada, uma gripe, febre. Ela foi fazer um exame e viram uma mancha no pulmão. E só descobriram isso até agora. (Cuidadora)

Isso aconteceu assim: Eu fiz uma consulta lá em Minas Gerais, com uma médica de lá, ela é cardiologista. Essa médica pediu uma chapa, eu fiz o raio-x e ela falou comigo assim: "Olha, a senhora está com uma mancha no pulmão". Só que eu não levei nada a sério, pensei, "Ah, isso é uma coisa à toa". Mas só que na hora em que eu resolvi levar a sério, já era um pouco tarde. (Mulher, mineira, 68 anos, aposentada, casada, seis filhos)

É porque eu tenho pneumonia aguda e acusou os pulmões, agravou o meu pulmão. Ficou pretinho porque eu fumava. (Mulher) 
Encontramos algumas imagens opostas ("murcho" versus "inchado"; "esburacado" versus "tampado/colado"). Aqui, fica claro como não estão em oposição necessariamente um "pulmão sadio" e um "pulmão doente". Por um lado, o "pulmão esburacado" é o problema: com "o enfisema ficava cheio de buraco o pulmão, como se fosse um balão, cheio de buraco". Outra senhora explicou que seu "pulmão está cheio de buraquinhos, todo perfurado por causa da tuberculose". Por outro lado, os "buracos" podem se referir, imaginamos, aos "alvéolos" ou "bronquíolos", naturais da constituição pulmonar. Uma senhora recebeu a explicação da médica, que lhe disse: "Você tampou aqueles buraquinhos que você tinha tudinho com a fumaça do cigarro". Ora o pulmão era visto como adoecido porque se tornava "esburacado", ora porque ficava "tampado".

As imagens descritas por essas pessoas retrataram como o pulmão foi lesionado e se tornou enfraquecido progressivamente depois de alguma experiência (fumo, fogão à lenha, pneumonia recorrente, tuberculose não tratada etc.). Essa debilidade tornava o órgão mais suscetível a desenvolver a DPOC. Doenças mal diagnosticadas e malcuidadas, a falta de recursos e dedicação para os tratamentos, condições de pobreza foram algumas das razões para que as doenças do pulmão tivessem "piorado" ao longo do tempo. A DPOC, portanto, parecia ser uma doença que se instalava depois de um tempo de vida, era tida como "doença da velhice" ou de um "pulmão envelhecido", mas também um "pulmão sofrido" ao longo do tempo.

Muitas pessoas disseram que nunca tinham ouvido falar em "DPOC" antes de receberem esse diagnóstico ali no hospital universitário. Não tinham parentes na família que haviam recebido esse diagnóstico. Essa era uma informação relevante porque a família, em primeiro plano, era a referência de um rol patológico possível. Um senhor lembrou, "Eu perguntei logo à médica, quando ela me falou que minha doença era no pulmão, eu perguntei para ela se eu era tuberculoso. Porque eu tinha uma prima com tuberculose" (Homem, pernambucano, 75 anos, casado, aposentado). Algumas das doenças pulmonares conhecidas e reconhecidas entre os parentes eram: gripe, bronquite, asma, tuberculose e pneumonia.

Tuberculose e pneumonia foram muito mencionadas e, em geral, tidas como doenças muito mais graves e fatais do que a DPOC. Uma senhora ilustrou isso ao lembrar de um trecho do diálogo que teve com a médica, às vésperas da revelação do diagnóstico:

Eu disse assim, 'Doutora, a senhora pode me dizer, seu eu tiver câncer, você pode me dizer, por que eu não tenho medo, porque eu tenho fé em Deus, pode ser tuberculose, pode me dizer que eu não tenho medo'. Eu falei assim. Eu tenho muita fé em Deus. (Mulher, piauiense, 70 anos, aposentada, 14 filhos)

É bom lembrar que, para pessoas nessa faixa etária, a representação da pneumonia e tuberculose ainda remetia à forma como essas doenças foram percebidas no início do século XX. Casas de repouso, clínicas de tratamento, isolamento compulsório e risco de contágio foram facetas dessas duas doenças - tuberculose e pneumonia - que construíram o estigma que essas pessoas podem ter visto em sua infância e adolescência (NOGUEIRA, 2009). Contágio, discriminação e morte - elementos tão intricados entre si - também foram identificados por Pinto et al (2008: 2811) entre os pacientes de DPOC entrevistados em um hospital universitário de Fortaleza (CE), sobretudo porque o "catarro" foi a principal característica corporal percebida e indesejada entre eles. O catarro, também presente na tuberculose e pneumonia, era tido como um forte vetor de contaminação e transmissão dessas doenças. Os entrevistados tendiam, por isso, a se isolar ainda mais quando recebiam o diagnóstico de DPOC. 
Com essas doenças pulmonares do século XX, as doenças pulmonares do século XXI são comparadas e contrastadas. Esse é o pano de fundo que identificamos com força entre as entrevistadas que, como indicado acima, tinham sido crianças e adolescentes na primeira metade do século passado. Assim, ouvir que o diagnóstico era uma DPOC, doença crônica e não contagiosa, figurou como um alívio, como um cenário menos grave e alarmante do que uma tuberculose. Uma doença menos grave ou até mesmo uma não doença foram relacionadas à DPOC, sempre em comparação com essas outras duas doenças pulmonares (TB e pneumonia). Nesse sentido, uma senhora cearense de 51 anos e que trabalhou como auxiliar de administração nos contou:

Entrevistadora: E a senhora considera a DPOC como uma doença?

Mulher: Eu já me acostumei com essa doença. Só que eu tenho que estar sempre cuidando.

Entrevistadora: E a senhora se vê como doente?

Mulher: Não.

A DPOC poderia, portanto, não ser percebida como uma “doença”, mas algo mais brando, em relação às outras doenças pulmonares. Ou, quando muito intensificada, ser associada diretamente às outras doenças pulmonares. Dessa forma, algumas pessoas achavam que seu adoecimento atual em muito se aproximava da "pneumonia" ou da "tuberculose”. Quer dizer, algumas pessoas não se percebiam com "DPOC”, por exemplo, mas com uma "pneumonia há muitos anos", como uma senhora (goiana, 60 anos, costureira, casada, três filhos), que explicou estar há uma década nessa situação. Um senhor contou que "estava ali no hospital universitário devido a uma pneumonia que havia pegado quando mais novo $e$ que ainda não havia sarado". Ele havia vindo do Piauí e "em sua cidade não havia pneumologista". Uma senhora disse, "Essa minha doença sempre foi uma pneumonia silenciosa" (brasiliense, 41 anos, solteira). Um senhor explicou que não podia mais beber e, à época da entrevista, estava abstêmio havia dois meses. Logo em seguida, disse, "Você sabe, a pneumonia é assim, se beber coisa gelada ela volta. Vai complicando" (cearense, 76 anos, casado, seis filhos). Muitas achavam que a tuberculose e a pneumonia eram as doenças que haviam levado à DPOC.

Numa classificação quente/frio, tão comum entre as sociedades latino-americanas, tuberculose e pneumonia eram percebidas como "frias". Isso quer dizer que, na prática, só melhorariam com alimentos, ambientes e atividades "quentes", isto é, com o contraste térmico. Essa relação entre doenças e cuidados opostos e complementares é conhecida na Antropologia como "síndrome frio-quente" (IBÁÑEZ-NOVION, 2012: 113-132). Por exemplo, "tomar gelado", como o senhor abstêmio acabou de lembrar, tendia a afetar e piorar as doenças "frias" e, por tabela, o estado do adoecido. Portanto, o fato de a DPOC estar estreitamente ligada a essas duas outras doenças "frias" (pneumonia e tuberculose), faz também com que o "frio" seja evitado. É por isso que, nesse rol de elementos gélidos perigosos, o oxigênio concentrado - percebido corporalmente como mais frio do que o oxigênio encontrado na atmosfera - seja percebido como potencialmente perigoso e, consequentemente, evitado. Aqui, portanto, repousa uma das explicações para que a oxigenoterapia não seja seguida à risca pelos pacientes. 


\section{As causas da DPOC}

Três foram os conjuntos de causas mais recorrentemente encontradas ao longo das 28 entrevistas realizadas. O primeiro conjunto se refere ao fumo. O segundo às condições e aos contextos em que essas pessoas trabalharam ao longo da vida. O terceiro conjunto de causas, por fim, se relaciona às condições climáticas em que viviam ou pelas quais precisavam transitar.

Em geral, o cigarro foi a razão mais mencionada como tendo provocado a debilidade dos pulmões e o consequente desenvolvimento da DPOC. As pessoas lembravam da presença do cigarro, sempre com mensuração cronológica: "Fumei 40 anos", "Fumei por cinco décadas", "Fumei desde os oito anos de idade". Mas o fumo era contextualizado e as pessoas nos trouxeram mais informações sobre como essa prática lhes foi apresentada e/ou como passou a ser parte de seu cotidiano. Foram menções, a nosso ver, que claramente se remeteram a razões externas e não necessariamente a escolhas, desejos e comportamentos iniciados individualmente:

Eu aprendi a fumar sabe com que idade? Com cinco anos, brincando nos brinquedinhos, pegava a folha de fumo, fazia cachimbo e fumava. Era pra dizer que estava cuidando da casinha da gente, aprendi a fumar. (Mulher, pernambucana, 73 anos, casada, seis filhos)

Eu comecei porque minha mãe me dava. Eu trabalhava na roça e mãe dava um cigarro pra nós fumarmos porque lá tinha muito mosquito. A gente capinando e o mosquito ia chegando. Aí foi quando eu aprendi a fumar. (Mulher, piauiense, 69 anos, viúva, aposentada, 14 filhos)

É uma fibrose pulmonar. Diz que é através do fumo, mas eu nunca fumei, mas meu marido fumava muito. (Mulher, maranhense, 76 anos, separada, 10 filhos)

Em segundo lugar, os locais de trabalho foram responsabilizados pelo adoecimento pulmonar. Encontramos várias menções nesse sentido ao longo das conversas:

Ah, eu acho que trabalhei com muito tóxico. Eu era técnico de manutenção de supermercado. (Homem, 76 anos, cearense, casado, seis filhos)

Eu trabalhava em um ar condicionado. Eu acho que foi isso. (Mulher, cearense, 51 anos, auxiliar de administração, solteira, dois filhos)

Fui costureira e fazia trabalhos com cotton, que solta uma penugem, uma poeira que era inalada. (Mulher, costureira)

O doutor perguntou pra mim, "A senhora usou o fogo de lenha?" Eu disse, "Doutor, eu vim usar fogo de gás um dia desses". E eu morava bem no interior, perto da pista principal e tinha muita poeira. (Mulher, piauiense, 69 anos, viúva, aposentada, 14 filhos)

Eu trabalhava de eletricista. Onde eu trabalhava tinha muito bicho morto, carcaça de bicho, muito rato, e eu ficava em espaço pequeno, ficava em espaço pequeno, não tinha onde eu ficar naquelas mansões grandes. Então, aquilo ali me causou um dano terrível porque eu passei a sofrer esse problema, eu não tinha problema médico nenhum até os 45 anos. (Homem, goiano, 61 anos, casado)

Eu trabalhava de marceneiro, tinha uma oficina de marcenaria. (Homem, sul-riograndense, 72 anos, casado, marceneiro aposentado)

Eu nem sei explicar como começou, hoje eu sento e fico todas as horas do dia sentado aqui, sentado e meditando. Eu já trabalhei com muito ingrediente que prejudicou o pulmão, mas eu não sabia, na época quase ninguém sabia de nada. E a última coisa que eu trabalhei para me prejudicar, para chegar ao estado final, foi o cimento. Eu 
também já trabalhei com enxofre, no cais do porto, em navio. Mas hoje eu fico pensando porque minha profissão era sapateiro e eu aprendi a profissão muito cedo, com 10 anos. Eu já passei pra profissional com 10 anos. Eu trabalhei muito com cola de sapato e eu penso que aquilo ali, aquele cheiro forte que a gente sente, deve ter feito mal. Eu era novo, caboclo forte e praticava esporte. Essas coisas parecem que não me fizeram mal na época porque eu jogava futebol. (Homem, 75 anos, pernambucano, aposentado, união estável, sete filhos)

Por fim, como terceiro conjunto de razões, as pessoas lembraram do "frio", "friagem", "clima", "vento" e "chuva" como elementos que pioravam a saúde em geral e o pulmão, em especial. Aqui, remetemos à discussão que iniciamos acima, sobre a "síndrome frio-quente", em que doenças tidas como "frias" precisam de tratamentos "quentes", opostos termicamente. Um senhor disse: "Tomei muita friagem, lama, ficava molhado. Vivi na fazenda e lá pegava muita friagem, além de ficar muito na lama, o que comprometeu meu pulmão". O clima poderia piorar uma doença simples ou poderia, de fato, iniciar e agravar as doenças atuais, como a DPOC. O frio dificultava a respiração e o funcionamento das vias aéreas. $\mathrm{O}$ ar que saía dos concentradores de oxigênio era mais frio e, por algumas pessoas, tido como um ar nocivo, também prejudicial. Por isso, o ar do concentrador era evitado em dias mais frios ou em dias em que a doença pulmonar estivesse "atacada". Recomendamos, portanto, que o frio seja considerado no idioma das doenças pulmonares e também no cálculo do bom cuidar da saúde.

Considerar a forma como as pessoas identificavam a causa de suas doenças é muito importante porque informa como percebiam as doenças e como decidiam tratá-las. Quando a pessoas adoecida não era identificada como responsável pelo desenvolvimento de sua doença, sua posição como vítima ficava mais pronunciada e, caso estivesse numa situação de dependência de cuidados externos, seus cuidadores tinham muito mais disponibilidade para lhe assistir. Os três conjuntos de causas que identificamos tenderam a localizar as razões da DPOC externamente à pessoa adoecida. Mesmo no fumo, revelaram como a prática foi introduzida por outras pessoas, como a mãe, o marido, as outras crianças na brincadeira etc. No entanto, em uma ou outra entrevista, ficou claro como a cuidadora (geralmente, esposa) culpava o marido por décadas de fumo e, claramente, tinha indisposição e mágoa para lhe prestar ajuda na atualidade. Assim, fica a sugestão de conhecer, para cada adoecida e sua respectiva família, como a DPOC é percebida, sobretudo como as pessoas envolvidas identificam o início e a causa da doença e como organizam cuidadoras e arranjos de cuidado dessa doença crônica. Acreditamos que, dessa forma, será mais fácil entender a forma como o auto/cuidado acontece, aumentando as chances de conseguir desenhar um tratamento que faça mais sentido e seja mais aceito.

Expectativas de cura

Como vimos acima, os pulmões eram imaginados como órgãos delicados e bastante vulneráveis às sequelas de pneumonia, tuberculose, asma, bronquite e gripe. As duas primeiras doenças, como pontuamos acima, eram tidas como mais graves do que a DPOC. Além disso, muitas das causas da DPOC eram tidas como externas ao comportamento do indivíduo, como a prática do fumo, os riscos ocupacionais e o clima. A partir desses dados, notamos que as pessoas sustentavam uma expectativa de cura em relação ao seu estado. Isso quer dizer que, por um lado, não viam a DPOC como grave nem fatal, como a tuberculose foi entendida no início do século XX. Por outro lado, parece que, se suspendessem as causas 
externas, isto é, deixassem de fumar, passassem aos fogões a gás, evitassem a exposição às substâncias tóxicas e ao frio, a DPOC poderia melhorar e, num cenário otimista, chegaria à cura.

Quando perguntamos sobre os planos futuros, uma senhora disse: "Eu espero que o tratamento acabe. Eu só penso em ficar livre desse oxigênio e viver minha vida como era sempre tranquila". Uma segunda explicou: "Eu espero a melhora. Que a médica consiga pelo menos uma coisa que resolva, uma coisa definitiva para esse pulmão aî" (mulher, separada, aposentada). Outra disse que desejava "melhorar a cada dia" (mulher, maranhense, 76 anos, separada, 10 filhos). Uma última nos contou:

\begin{abstract}
A médica me falou que podia ser reversível esse meu problema. Eu caminho, eu vou a pé e volto a pé do posto de saúde e não canso. Antes, eu não caminhava essa mesma distância. (...) Eu tomo o Torazeque que ela passou. Mas Deus me abençoa, todo dia eu peço a Deus para ele lavar e passar a mão, para deixar meu pulmão do jeito que ele era. (Mulher, piauiense, 69 anos, viúva, aposentada, 14 filhos)
\end{abstract}

Sobre o que esperava do tratamento, essa senhora foi eloquente: "Com muita fé em Deus, eu quero ficar boa e logo de cara”. Inclusive, como já indicamos acima, era a concepção de que a DPOC era uma evolução da pneumonia ou da tuberculose, doenças sofridas há mais tempo. Assim, o fato de a pneumonia e a tuberculose serem curáveis hoje em dia, fazia com que a DPOC também pudesse ser.

Por outro lado, ouvimos de várias médicas e técnicas do Ambulatório que pacientes em situação de DPOC eram "pacientes muito graves e sem muita terapêutica”. Só poderiam oferecer "medidas paliativas". Eventualmente, conseguiam, às custas do oxigênio domiciliar e dos medicamentos, fazer desaparecer os sintomas da doença e, em último caso, acompanhar a progressão da doença. É o que a equipe chamava de fazer a "manutenção da doença", numa clara alusão aos cuidados paliativos do final da vida. Percebemos um ruído significativo entre profissionais de saúde e suas pacientes, sendo que as primeiras acreditavam na limitação terapêutica que podia ser oferecida à DPOC. Enquanto as segundas mantinham uma expectativa de cura.

Os procedimentos que, em vez de melhorarem o estado de saúde, respondiam de modo adverso geravam uma forte sensação de ambiguidade e de desconfiança em relação aos profissionais de saúde, aos medicamentos e aos serviços oferecidos pelo hospital como um todo. Por exemplo, um senhor nos contou que se sentia muito melhor e possuía mais fôlego antes do início das sessões de quimioterapia a que foi submetido para estabilizar sua fibrose pulmonar. Era difícil entender como um tratamento poderia ter lhe debilitado ainda mais. E muitas pessoas estranhavam o mal-estar que sucedia a espirometria, exame clínico para medir a capacidade respiratória.

No que concerne à gestão da DPOC, esta ambiguidade e desconfiança foram notadas por muitas entrevistadas em relação a vários dos procedimentos oferecidos pelo Ambulatório de Pneumologia, como por exemplo:

a. as longas crises de tosse e o mal-estar que o exame de espirometria poderia desencadear;

b. o exame de gasometria que era extremamente doloroso;

c. a constância de consultas e exames e a dificuldade para realizar tantos deslocamentos até o hospital; 
d. o cansaço que aumentava mesmo com a realização do tratamento (medicamentos e oxigenoterapia);

e. a prescrição da oxigenoterapia como medicamento que limitava as interações sociais das pessoas e, em grande medida, as isolavam em casa perto do concentrador de ar;

f. a experimentação com várias gerações e combinações de medicamentos, sem resultados positivos;

g. os medicamentos à base de corticoides que provocavam retenção de líquido e, por consequência, aumento do peso e a impossibilidade de concorrer ao transplante pulmonar.

Ou seja, essas situações compõem uma série de práticas terapêuticas que, muitas vezes, podiam gerar efeitos colaterais inesperados e, por tabela, novas demandas terapêuticas. Muitas vezes essa cadeia negativa de consultas, exames e medicamentos nem sempre era comunicada durante os encontros com os profissionais de saúde nesse Ambulatório. Com isso, os sinais de bem-estar e recuperação, esperados de um tratamento médico, não eram vislumbrados por muitas das entrevistadas. $\mathrm{O}$ pacto terapêutico entre profissional e paciente se enfraquecia paulatinamente, bem como a confiança necessária para aderir aos tratamentos.

\section{Considerações finais}

Um importante pressuposto desse artigo é a firme aposta na rentabilidade do encontro interdisciplinar para compreender, traduzir e facilitar tratamentos de saúde. A Antropologia da Saúde tem, desde os primórdios da área, demonstrado profundo interesse nesse diálogo e sido criativa ao propor entendimentos mais aprofundados sobre experiências de adoecimento.

Para esse conjunto de entrevistadas, o pulmão é tido como um órgão vital, delicado e muito suscetível ao mundo externo. Ele não tem uma consistência estática ao longo da vida e pode ser alterado mediante o fumo, o contexto do trabalho, as mudanças climáticas. A DPOC é um estado associado a outras patologias pulmonares, como a pneumonia e a tuberculose. Por conta dessa proximidade, a DPOC também é compreendida como "fria" e todo tipo de tratamento "frio" terá mais dificuldade de ser aceito e adotado.

Ficou-nos muito claro também que o cuidado com a DPOC depende das razões para seu aparecimento, isto é, quanto mais o indivíduo adoecido for responsabilizado pelo diagnóstico, menos disponibilidade a família terá para oferecer apoio continuado. Além da casa, o hospital é espaço muito importante das relações de cuidado, dado o acompanhamento intenso exigido pelo estado de cronicidade da DPOC. Contudo, consultas, exames e medicamentos que geram efeitos colaterais ou inesperadamente negativos, dotam as pacientes de desconfiança em relação à biomedicina. Deve haver também cuidado com a comunicação e transparência sobre os processos, arranjos e limites terapêuticos. 


\section{Referências}

BECKER, Gaylene; JANSON-BJERKLIE, Susan; BENNER, Patricia; SLOBIN, Kathleen; FERKETICH, Sandra. "The dilemma of seeking urgent care: Asthma episodes and emergency service use". Social Science \& Medicine, 37 (3): 305-313, 1993.

CARDOSO DE OLIVEIRA, Roberto. "O trabalho do antropólogo: olhar, ouvir, escrever”. In: O trabalho do antropólogo. Brasília/São Paulo: Paralelo 15/Editora UNESP, 1998. pp. 17-35.

CHARON, Rita. Narrative medicine: Honoring the stories of illness. Oxford: Oxford University Press, 2006.

CHAZAN, Lílian Krakowski. Vestindo o jaleco: Reflexões sobre a subjetividade e a posição do etnógrafo em ambiente médico. Cadernos de campo, 14: 15-32, 2005 .

DUARTE, Luiz Fernando Dias. Da vida nervosa nas classes trabalhadoras urbanas. Rio de Janeiro: Jorge Zahar/CNPq, 1986.

FLEISCHER, Soraya. Descontrolada: uma etnografia dos problemas de pressão. São Carlos: Editora da Universidade Federal de São Carlos, 2018.

FLEISCHER, Soraya. O cansaço como categoria norteadora das experiências de adoecidos pulmonares. Saúde e Sociedade, 24 (4): 4-18, 2015.

GONÇALVES, Helen; COSTA, Juvenal Dias da; MENEZES, Ana Maria B.; KNAUTH, Daniela; LEAL, Ondina Fachel. A adesão à terapêutica da tuberculose em Pelotas, Rio Grande do Sul: na perspectiva do paciente. Cadernos de Saúde Pública, 15 (4): 777-787, 1999.

IBÁÑEZ-NOVION, Martin Albert. "A síndrome frio-quente". In: FLEISCHER, Soraya; SAUTCHUK, Carlos Emanuel (orgs.). Anatomias populares: A Antropologia Médica de Martín Alberto Ibánez-Novión. Brasília: EdUnB, 2012. pp. 113132.

IBÁÑEZ-NOVION, Martin Alberto; IBÁÑEZ-NOVIÓN, Olga Cristina e TRINDADE SERRA, Ordep. "O anatomista popular: um estudo de caso". In: FLEISCHER, Soraya; SAUTCHUK, Carlos Emanuel (orgs.). Anatomias populares: A antropologia médica de Martin Alberto Ibáñez-Novión. Brasília: UnB, 2012.

JARDIM, José Roberto; OLIVEIRA, Júlio A. de; NASCIMENTO, Oliver. "Por que um novo Consenso de DPOC? Jornal de Pneumologia 30 (5): 7-8, 2004.

MALINOWSKI, Bronislaw. Os Argonautas do Pacífico Ocidental. São Paulo, Coleção os Pensadores: Ed. Victor Civita, 1984 (1922).

MARTINS, Raysa. Mergulhadores no Distrito Federal: Um estudo antropológico sobre doenças pulmonares e o uso de oxigenoterapia. Dissertação (Mestrado em Antropologia Social), Universidade de Brasília, 2014.

NOGUEIRA, Oracy. Vozes de Campos do Jordão: experiências sociais e psíquicas do tuberculoso pulmonar no estado de São Paulo. Rio de Janeiro: Editora Fiocruz, 2009. 
PINTO, Juliana Maria de Sousa; VIEIRA, Luiza Jane Eyre de Souza; NATIONS, Marilyn K. Sopro de vida: experiência com a doença pulmonar obstrutiva crônica na pobreza urbana de Fortaleza, Ceará, Brasil. Cadernos de Saúde Pública, 24 (12): 2809-2818, 2008.

SCHUSTERA, John, BEUNEB, Erik; STRONKSC, Karien. Metaphorical constructions of hypertension among three ethnic groups in the Netherlands. Ethnicity \& Health, 16 (6): 583-600, 2011.

SOUSA, Clóvis Arlindo de; CÉSAR, Chester Luiz Galvão; BARROS, Marilisa Berti de Azevedo; CARANDINA, Luana; GOLDBAUM, Moisés; PEREIRA, Júlio Cesar Rodrigues. Doença pulmonar obstrutiva crônica e fatores associados em São Paulo, SP, 2008-2009. Revista de Saúde Pública, 45 (5): 887-896, 2011.

TORRES, Karla Dala Paula; CUNHA, Geraldo Marcelo; VALENTE, Joaquim Gonçalves. Tendências de mortalidade por doença pulmonar obstrutiva crônica no Rio de Janeiro e em Porto Alegre, 1980-2014. Epidemiologia, Serviço e Saúde, 27 (3): 1-11, 2018. 


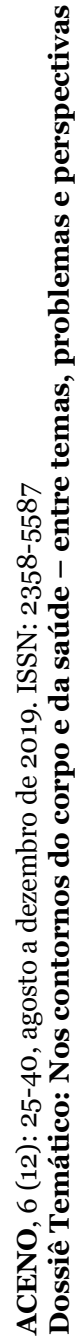

$$
40
$$

